\title{
The Implementation Of Softskill essences ON Vocational Education
}

\section{Implementasi Nilai-Nilai Softskill Pada Pendidikan Kejuruan}

\author{
Sukardi ${ }^{1)}$, Ahmad Eko Suryanto ${ }^{2)}$, Ratna Pancawati ${ }^{3)}$ \\ 1), 2), 3) Program Studi Pendidikan Teknik Mesin, FKIP, UPR \\ Kampus Unpar Tunjung Nyaho, Jl. H. Timang, 73111A \\ e-mail: sukardioto@fkip.upr.ac.id
}

\begin{abstract}
At present days stakeholders require the graduates who have the technical skills (Hardskill) as well possess the soft skills. The Hardskills are just not sufficient to deal with the qualification of employers in the real-world of workplace, but need to be equipped with soft skills in order to shape the integrated capabilities as needed by users. To form the student's soft skills can be implemented through the coaching program in formal learning activities and extracurricular activities. The softskill development of students is necessary to be achieved with concrete efforts, namely: 1) the existence of policies that legalize the implementation of soft skill based on the extracurricular activities in each education unit; 2) systematic and planned soft skills development program; and 3) the softskill dissemination is carried out synergistically involving all parties.
\end{abstract}

Keywords: Hardskill, Softskill, Vocational Education.

\section{ABSTRAK}

Saat ini stakeholders menginginkan lulusan yang selain memiliki kemampuan teknikal (hardskill) juga memiliki softskill. Hardskill saja tidak cukup untuk menjawab kebutuhan pengguna jasa di dunia kerja, namun perlu dilengkapi dengan softskill agar dapat terbentuk kemampuan yang terintegrasi sesuai yang dibutuhkan oleh pengguna. Untuk membentuk softskill peserta didik caranya dapat dilakukan melalui pembinaan pada aktifitas pembelajaran dan aktifitas ekstrakurikuler. Pembinaan softskill peserta didik, perlu dilakukan dengan upaya nyata yaitu: 1) adanya kebijakan yang melegalisasi pelaksanaan kegiatan ekstrakurikuler berbasis softskill di masing-masing satuan pendidikan; 2) penyusunan program pengembangan softskill secara sistematis dan terencana; dan 3) implementasi softskill dilakukan dengan sinergis yang melibatkan semua pihak.

Kata Kunci: Hardskill, Softskill, Pendidikan Kejuruan.

\section{PENDAHULUAN}

Pendidikan Kejuruan memiliki peran terhadap pengembangan kualitas Sumber Daya Manusia (SDM) yang bermanfaat bagi masyarakat, dunia industri (Dudi) dan pembangunan nasional. Pendidikan Kejuruan dijelaskan dalam Undang-Undang tentang Sistem Pendidikan Nasional Nomor 20 Tahun 2003, mempunyai tujuan menyiapkan peserta didik untuk siap memasuki dunia kerja. Sementara itu, kemajuan teknologi yang diaplikasikan di industri menuntut adanya SDM yang memiliki kemampuan beradaptasi dan daya saing.

Tingkat persaingan SDM di pasar kerja nasional dan internasional terus meningkat seiring dengan peningkatan pemanfaatan ilmu pengetahuan dan teknologi baru pada berbagai bidang dan kebutuhan tingkat profesionalisme yang semakin tinggi. Namun, realitasnya sebagaimana pernyataan Kepala Dirjen Dikdasmen Depdiknas, Suyanto menyatakan bahwa "hasil studi hanya 50\% lulusan Sekolah Menengah Kejuruan yang terserap dunia industri" (Suara Merdeka, 20 Mei 2009). Data Badan Pusat Statistik (BPS) Tahun 2008 juga mencatat jumlah pengangguran
Iulusan Sekolah Menengah Kejuruan lebih dari 1,6 juta orang $(17,26 \%)$ dari 9,39 juta. Kementrian Pendidikan Nasional Joko Sutrisno (dalam Kompas.com, 2010) menyatakan bahwa rata-rata hanya $10 \%$ tiap tahunnya siswa lulusan Sekolah Menengah Kejuruan yang melanjutkan ke perguruan tinggi, dan $50 \%$ terserap dunia kerja. Dengan demikian 40\% lainnya masih diragukan keberadaannya.

BPS mencatat bahwa angka pengangguran terbuka Indonesia mencapai 7,7 juta orang pada Agustus 2011. Jumlah $6,56 \%$ dari total angkatan kerja berdasarkan pendidikan dan didominasi lulusan SMA dan SMK. BPS juga menyebutkan pada Februari 2011, tingkat pengangguran terbuka tertinggi lulusan SMA mencapai 10,66\% dan SMK sebesar 10,43\%, (http://www.neraca.co.id/2011). Berdasarkan data terbaru dari BPS, jumlah penggangguran di Indonesia masih terbilang sangat besar. Pada periode Agustus 2012 mencapai 7,2 juta orang, lulusan SMA/SMK paling banyak menyumbang angka pengangguran. 
Angka pengangguran berdasarkan level kelulusan pendidikan yang pertama adalah Sekolah Menengah Kejuruan (SMK) 9,87\%, Sekolah Menengah Atas (SMA) 9,6\%, Sekolah Menengah Pertama 7,76\%, Diploma I/II/III $6,21 \%$, Universitas $5,91 \%$, dan SD ke bawah dengan $3,64 \%$.

Fenomena ini menunjukan bahwa Sekolah Menengah Kejuruan belum mampu memenuhi harapan. Tingginya angka pengangguran lulusan Sekolah Menengah Kejuruan menujukkan bahwa mutu pendidikan Sekolah Menengah Kejuruan dengan kehidupan nyata masih rendah. Sisi lain tidak terserapnya Iulusan, sebagian besar Iulusan Sekolah Menengah Kejuruan di Indonesia bukan saja kurang mampu menyesuaikan diri dengan perkembangan ilmu dan teknologi tetapi juga kurang mampu mengembangkan diri dan karirnya di tempat kerja (Depdiknas, 2004).

Penyelenggaraan pendidikan Sekolah Menengah Kejuruan mengacu kepada tiga aspek pembentuk kompetensi, yakni 1) kognitif atau pengetahuan dan pemahaman konsep, 2) afektif yaitu kecenderungan emosional dalam menerima suatu kompetensi, dan 3) psikomotor atau tindakan yang dilandasi dengan penjiwaan (Sukmara, 2007). Dengan demikian keberhasilan pendidikan kejuruan bukan hanya dilihat dari segi ketrampilan (hardskill) saja, melainkan juga aspek lain yang saling mempengaruhi.

Hardskill dalam dunia kerja tidak menjadi persoalan, kerena industri berasumsi bahwa hardskill dapat ditransfer kepada siswa dengan waktu yang lebih cepat dibandingkan dengan sikap dan pengetahuan yang membutuhkan proses yang panjang. Selama ini proses bembelajaran lebih berorientasi pada hardskill yakni keterampilan teknis dalam membuat/ memproduksi barang atau jasa sesuai tuntutan pasar. Hal ini dipertegas oleh Santoso, (2008) (dalam Sudjimat, 2010) bahwa 90\% pendidikan menitikberatkan pada hardskill, sedangkan softskill hanya $10 \%$.

Hasil research di Eropa menunjukkan bahwa softskill memiliki peran penting dalam menentukan kesuksesan seseorang dalam dunia kerja. Hardskill merupakan persyaratan minimal (20\%) bagi seseorang untuk memasuki bidang pekerjaan tertentu, sedangkan softskill (80\%) akan menentukan pengembangan diri dalam suatu pekerjaan. Namun bukan berarti mengabaikan hardskill dalam dunia usaha dan dunia kerja atau dunia bisnis lainnya. Oleh karena itu menjadi tantangan dunia pendidikan kejuruan untuk mengintegrasikan softskill dan hardskill agar mampu menyiapkan SDM secara utuh yang memiliki kemampuan bekerja dan berkembang di masa depan.

Berdasarkan uraian masalah yang telah dikemukakan, tujuan penulisan artikel ini adalah : (1) Mengkaji hubungan antara softskill dengan kesuksesan karir di dunia kerja, dan (2) Mengkaji model pengembangan pembelajaran softskill dalam pendidikan kejuruan yang dapat mengintegrasikan kemampuan hardskill dan softskill secara terpadu.

\section{PEMBAHASAN}

\section{A. Hubungan Softskill dengan Kesuksesan Karir di Dunia Kerja}

Softskill merupakan keterampilan dalam berhubungan dengan orang lain atau interpersonal skills dan keterampilan dalam mengatur dirinya sendiri atau intrapersonal skills yang mampu mengembangkan unjuk kerja secara maksimal.

Atribut softskill dimiliki oleh setiap orang kadarnya berbeda-beda, dipengaruhi oleh kebiasaan berfikir, berkata, bertindak, dan bersikap. Namun, atribut ini dapat berubah dengan berlatih membiasakan diri dengan halhal yang baru (Saillah, 2008). Atribut softskills yang dibutuhkan di dalam dunia kerja dibagi menjadi 3 tingkatan, yaitu 1) Mastered: seharusnya dikuasai dan sangat penting, 2) Some mastery; seharusnya dikuasai berfungsi sebagai pelengkap, dan 3) Not yet mastey; sebagai pelengkap kesuksesan.

\begin{tabular}{|c|c|}
\hline & SOFT SKILLS RANKING \\
\hline 1 & Personal Effectiveness \\
\hline 2 & Flexibility \\
\hline 3 & Management \\
\hline 4 & Creativity/lnnovation \\
\hline 5 & Futuristic Thinking \\
\hline 6 & Leadership \\
\hline 7 & Persuasion \\
\hline 8 & Goal Orientation \\
\hline 9 & Continuous Learning \\
\hline 10 & Decision Making \\
\hline 11 & Negotiation \\
\hline 12 & Written Communication \\
\hline 13 & Employee Development/Coaching \\
\hline 14 & Analytical Problem Solving \\
\hline 15 & Teamwork \\
\hline 16 & Presenting \\
\hline 17 & Diplomacy \\
\hline 18 & Conflict Management \\
\hline 19 & Empathy \\
\hline 20 & Customer Service \\
\hline 21 & Planning/Organizing \\
\hline 22 & Interpersonal Skills \\
\hline 23 & Self-Management (time and priorities) \\
\hline
\end{tabular}

Sumber : Santoso (2008)

Era global, negara membutuhkan tenaga kerja yang kompetitif, adaptif dan antisipatif, terbuka terhadap perubahan, mampu belajar, terampil, mudah dilatih ulang, memiliki keterampilan dasar yang luas dan mampu mengembangkan diri. Berdasarkan beberapa penelitian, tenaga kerja yang baik harus memiliki softskill (kepemimpinan, kepribadian, dan motivasi), (Widarto dan Wijanarka, 2012). Untuk dapat mengikuti tatanan dunia global, Wagner (2008), dalam buku The Gap Prestasi 
global menulis tujuh kemampuan keterampilan bertahan hidup di era global, yaitu: (1) berpikir kritis dan problem solving, (2) kolaborasi di dalam networks dan kepemimpinan, (3) agility dan adaptasi, (4) inisiasi dan entrepreneursip, (5) komunikasi lisan dan tertulis, (6) mengakses dan menganalisis informasi, dan (7) rasa ingin tahu dan imajinasi.

Softskill merupakan kemampuan yang dapat meningkatkan kinerja kerja seseorang dan prospek karir. Softskill membantu individu untuk mengembangkan keterampilan kerja dan membuat mereka percaya diri untuk bekerja dalam lingkungan kerja yang berorientasi pada kinerja. Sehubungan dengan hal ini, adalah tugas para pendidik untuk mempersiapkan lulusan untuk menjadi kompetitif didunia kerja. Hasil penelitian menunjukkan bahwa lulusan yang memiliki softskill seperti sikap positif, komunikatif, pemecahan masalah dan lain-lain, memiliki jauh lebih baik kemungkinan bertahan di dunia kerja dibandingkan dengan lulusan yg kurang dalam keterampilan softskill-nya (Al-Mamun, 2012).

\section{B. Model Pembelajaran Untuk Mengintegrasikan Kemampuan Hardskill Dan Softskill}

Pendidikan merupakan proses dimana peserta didik akan memiliki pengetahuan (kognitif), sikap (apektif) dan ketrampilan (psikomotorik) guna bekal hidup yang layak di tengah-tengah masyarakat. Proses ini mencakup peningkatan intelektual, personal dan kemampuan sosial yang diperlukan bagi peserta didik sehingga tidak saja berguna bagi diri pribadi dan keluarga tetapi juga keberadaannya bermanfaat bagi masyarakat. Maka strategi yang dikembangkan dalam kurikulum pendidikan nasional harus selalu berdasarkan pada ketiga ranah di tersebut, baik dalam proses pembelajaran maupun evaluasi.

Sejalan dengan pengertian tersebut, Unesco (dalam Hary, 2008) menyatakan bahwa tujuan belajar yang dilakukan oleh peserta didik harus dilandaskan pada empat pilar yaitu learning how to know, learning how to do, learning how to be, dan learning how to live together. Dua landasan yang pertama mengandung maksud bahwa proses belajar yang dilakukan peserta didik mengacu pada kemampuan mengaktualisasikan pengatahuan dan ketrampilan yang dimiliki masing-masing individu dalam menghadapi segala jenis pekerjaan berdasarkan basis pendidikan yang dimilikinya. Dengan kata lain peserta didik memiliki kompetensi yang memungkinkan mereka untuk dapat bersaing memasuki dunia kerja. Sedangkan dua landasan lainya mengacu pada kemampuan mengaktualisasikan berbagai kemampuan yang ada pada masing-masing individu dalam suatu keteraturan sistemik menuju suatu tujuan bersama. Maksudnya bahwa untuk dapat menjadi seseorang yang diinginkan yang dapat hidup berdampingan bersama orang lain baik di tempat kerja maupun di masyarakat, harus mengembangkan sikap toleran, simpati, empati, emosi, etika dan unsur psikologis lain, dan inilah yang disebut dengan softskill.

Guru/dosen memiliki peran penting dalam menentukan arah dan tujuan pembelajaran. Kemampuan yang dikembangkan tidak hanya ranah kognitif dan psikomotorik semata yang ditandai dengan penguasaan materi pelajaran, melainkan harus juga pada ranah kepribadian peserta didik. Pada ranah ini peserta didik harus menumbuhkan rasa percaya diri sehingga menjadi manusia yang mampu mengenal dirinya sendiri yakni manusia yang berkepribadian yang mantap dan mandiri, manusia utuh yang memiliki kemantapan emosional dan intelektual, yang mengenal dirinya, yang mengendalikan dirinya dengan konsisten dan memiliki rasa empati.

Pendidikan softskill harusnya diuraikan di dalam kurikulum yaitu dalam proses belajar mengajar, dan hidden curiculum, yaitu dalam bentuk aturan bagaimana berinteraksi antara guru/dosen, karyawan, dan murid-murid lain dalam kehidupan di kelas secara nyata.

Al-hafizh (2013), menguraikan beberapa pendapat ahli kurikulum yang mengajukan konsepsi maupun pengertian tentang hidden curriculum, seperti: 1) Dreeben memfokuskan pada apa yang dipelajari di kelas sebagai suatu fungsi struktur sosial kelas dan latihan otoritas guru/dosen, 2) Kolhberg mengidentifikasikan hidden curriculum sebagai hal yg berhubungan dengan pendidikan moral dan peranan guru/ dosen dalam mentransformasikan nilai moral, 3) Henry cenderung pada hubungan antara peserta didik dengan guru/dosen, aturan untuk mengatur hubungan tersebut dan peranan aturan ini dalam mendidik untuk kepatuhan (decolitas), 4) Goodman, Friedenberg, Reiner \& Illich menggunakan konsepsi hidden curriculum sebagai aturan untuk mengidentifikasikan dan menjelaskan penguatan kelas dan norma sosial tertentu.

Pendidikan softskill harus menjadi gerakan simultan dalam kelas, melibatkan semua pihak yaitu pimpinan, guru/dosen, karyawan, peserta didik, pemerintah, dan masyarakat. Aspek softskill yang dikembangkan dikarakterisasi berdasarkan kebutuhan masyarakat lokal dan dunia industri yang menjadi mitra. Pendidikan softskill dimulai dari peserta didik masuk kelas, selama proses pembelajaran, sampai menjadi lulusan. Dengan demikian, dapat disimpulkan bahwa mulai di pintu gerbang sekolah untuk kembali ke luar gerbang sekolah selalu mendapatkan pendidikan softskill. Pendidikan tersebut akan menjadi kebiasaan, dan jika kebiasaan diinternalisasikan dalam kehidupan sehari-hari maka akan menjadi budaya. Sebagai suatu kegiatan yang tidak boleh dilupakan, bahwa pendidikan softskill adalah program yang harus terus dievaluasi.

Johnson (dalam Mariah dan Sugandi, 2010), menyatakan bahwa pengembangan softskill dalam pendidikan harus berlandaskan pada kehidupan nyata, berpikir tingkat tinggi, aplikatif, belajar berbasis masalah, pengajaran autentik, pengajaran berbasis relevansi, belajar berbasis proyek, belajar berbasis kerja, belajar berbasis layanan, dan belajar kooperatif.

Membekali peserta didik dengan softskill tidak berarti menambah mata pelajaran baru, tapi memberi nilai/makna pada pembelajaran. Hakikat pendidikan adalah memanusiakan manusia, sehingga pembelajaran mengarah kepada learning to know (knowing more), learning to do (doing best), learning to be (being better), dan learning to live together (living in harmony).

Dari sekian banyak model pembelajaran, beberapa di antaranya sangat baik untuk melatihkan softskill pada peserta didik, dan model-model tersebut antara lain Cooperative Learning (CL), Experiential Learning (EL) dan Contextual Teaching and Learning (CTL) (Mariah, Sugandi 2010, dan Widyawati, 2011).

Pengembangan softskills dapat dilakukan melalui beberapa cara, antara lain: 
a) Pengembangan Softskill Melalui Pembelajaran Afektif

Untuk mengasah softskill idealnya seorang memiliki kehidupan yang seimbang antara aktivitas akademik dan non-akademik. Dalam pembelajaran, faktor yang sangat berpengaruh adalah dimulai dari guru/dosen. Guru/dosen harus bisa menjadi living example. Dari mulai disiplin, kemunikatif, kepemimpinan, dan lain sebagainya.

b) Pengembangan Softskills Melalui Kegiatan

Ekstrakurikuler (non Akademik)

Banyak hal yang bisa dipelajari oleh para peserta didik dengan kegiatan non akademik, antara lain: 1) mengembangkan bakat, 2) melatih kemampuan berorganisasi, kolaboratif, dan berkomunikasi.

Pembinaan dalam pengembangan softskill selayaknya dilakukan secara terintegrasi antara kegiatan kurikuler dan ekstrakurikuler. Pada kegiatan kurikuler, muatan softskill ini perlu dibina dan dikembangkan dalam berbagai kegiatan, metode dan model pembelajaran. Sementara itu, dalam kegiatan ekstrakurikuler dapat dilakukan pembinaan secara terprogram dalam bentuk legalisasi atau kebijakan lembaga pendidikan.

Dari berbagai masukan, baik berasal dari industri maupun penelitian diketahui bahwa kegiatan non akademik (ekstrakurikuler) merupakan wahana yang sangat efektif dalam pengembangan/ pembinaan softskill. Proses pembinaan ini harus selalu dilakukan secara terencana dan terpadu. Penguasaan hardskil diibaratkan sebagai kekuatan roda belakang sepeda sebagai kekuatan yang mendorong arah sepeda. Sementara itu, softskill sebagai roda depan yang mengatur arah, akan dibawa ke mana sepeda tersebut.

c) Pengembangan Softskills Melalui Praktek Kerja Industri

Harapan utama penyelenggaraan praktik di dunia usaha/industri di samping keahlian profesional meningkat sesuai dengan tuntutan kebutuhan dunia usaha/industri, diharapkan juga peserta didik akan memiliki etos kerja yang meliputi: kemampuan bekeja sama tim, memiliki motivasi bekerja, inisiatif, kreatifitas, hasil pekerjaan yang berkualitas, disiplin waktu dan kerajinan dalam bekerja.

Oleh sebab itu, program praktik kerja industri pada pendidikan kejuruan harus terencana, terlaksana, dan dievaluasi dengan sistematis dan terprogram dengan baik.

\section{KESIMPULAN}

Saat ini pengguna jasa atau stakeholders menginginkan lulusan yang selain memiliki kemampuan teknikal (hardskill) juga memiliki softskills seperti motivasi tinggi, kemampuan beradaptasi, kompetensi interpersonal, dan orientasi nilai yang menunjukkan kinerja yang efektif. Dengan kata lain, kemampuan kognitif (hardskills) saja tidak cukup memadai untuk menjawab kebutuhan pengguna jasa di dunia kerja, namun perlu dilengkapi dengan softskills yang tinggi agar dapat terbentuk kemampuan yang terintegrasi dan mempunyai kompetensi yang dibutuhkan oleh pengguna.
Untuk membentuk softskill peserta didik caranya dapat dilakukan melalui pembinaan pada aktifitas pembelajaran dan aktifitas ekstrakurikuler.

Untuk mengoptimalkan pembinaan softskill peserta didik, perlu dilakukan dengan beberapa upaya nyata, di antaranya: 1) adanya kebijakan yg melegalisasi pelaksanaan kegiatan ekstrakurikuler berbasis softskill di masing-masing satuan pendidikan; 2) penyusunan program pengembangan softskill secara sistematis; dan 3) implementasi nilai softskill dilakukan dengan sinergis yang melibatkan semua pihak. Dengan demikian, pendidikan sebagai sistem selalu melibatkan adanya interaksi.

\section{DAFTAR PUSTAKA}

[1]. Al-Mamun, A. 2012. The Softskills Education for the Vocational Graduate: Value as Work Readiness Skills. British Journal of Education, Society \& Behavioural Science, 2(4): 326-338.

[2]. Hary. 2008. Mengembangkan Softskill Siswa. (online)(http://harysmk3.wordpress.com/2008/01/1 0/mengembangkan-soft-skill-siswa)

[3]. Mariah, S. dan Sugandi, M. 2010. Kesenjangan Softskills Lulusan SMK Dengan Kebutuhan Tenaga Kerja Di Industri. Jurnal Inovasi dan Perekayasa Pendidikan Vol. 3 Tahun Ke-1

[4]. Santoso, S. 2008. Profil Softskills Guru Prodi Teknik Gambar Bangunan Bidang Keahlian Teknik Bangunan di SMKN 1 Nganjuk. Jurnal. (online)(http://slametsantosomultiply.com/journal/i tem/8)

[5]. Saillah, I. 2008. Pengembangan Softskill di Perguruan Tinggi. LPPM ITB

[6]. Sudjimat, D. A. 2010. Pengembangan Model Pendidikan Softskill Melalui Pembelajaran Pada Prodi Pendidikan Teknik Mesin FT UM. Jurnal Vol. 33, No. 2, Malang: Universitas Negeri Malang

[7]. Sobandi, B. 2009. Optimalisasi Softskill Melalui Pembinaan Organisasi Kemahasiswaan. Lokakarya Peningkatan Intensitas dan Volume Kegiatan Kemahasiswaan Melalui Workshop Pengembangan Soft Skill Mahasiswa Universitas Bung Hatta Padang.

[8]. Tim Penyusun. 2009. Draft Buku Panduan Penerapan Softskill. Universitas Negeri Gorontalo.

[9]. Widyawati, S. 2011. Pengembangan Softskill dalam Pendidikan Sebagai Bekal Kewirausahaan. Jurnal Seni Budaya Vol. 9 No.1. ISI Surakarta

[10]. Widarto dan Wijanarka, B.S. (Tanpa Tahun). Softskills Education For Preparing Vocational Secondary High School In Producing Skilled Graduates. International Seminar on Vocational Education and Training ISBN: 978-602-97249-0-5. 